\title{
Dairy product and wine in funerary rituals: the case of a hellenistic etruscan tomb
}

\begin{abstract}
A study to gain more knowledge on funeral set in an Etruscan Hellenistic tomb (end of the IV, beginning of the III century, B.C.) was carried out on 8 vessels ( 2 black-glazed jugs and 2 black-glazed bowls, 1 unglazed jug and 3 unguentaria). Every find was analyzed by GC-MS to determine the biomarkers of their ancient content. Analysis showed that white wine is the main funerary offering, attested in all the wine vessels (jugs and bowls). Surprisingly, the unguentaria did not contain perfumed oil but a dairy product for one vessel (milk?) and an animal fat balm for the 2 others. These data allow for a better understanding of the final act of the Etruscan funeral ritual, in regard to the organic products (wine, milk and balm) used and left to the dead.
\end{abstract}

Keywords: hellenistic etruria, contents of ceramics, biomolecular archaeology, funerary rituals and practices, perfume vases, wine vases, black-glazed ceramics, unguentaria
Volume I Issue 6 - 2017

\author{
Dominique Frère,' Nicolas Garnier² \\ 'Professor, Université de Bretagne Sud, France \\ 2Director of the LNG, France
}

Correspondence: Dominique Frère, Université de Bretagne Sud, France, Email frere@univ-ubs.fr

Received: June 30, 2017 | Published: September 15, 2017

\section{Introduction}

The Etruscans built the first civilization in Italy between the Arno and Tiber rivers. From the 8th to the 4th century B.C., they developed a rich and original society in close relationship with the Greek and Italic worlds. ${ }^{1}$ Throughout the Hellenistic period (4th-2nd), the interactions with the powerful city of Rome have increased until the conquest was followed closely by the Romanization. ${ }^{2}$ Access to the Etruscan society is limited by the nature of our sources: the loss of the sacred literature of the Etruscan people leaves us with only Greek and Latin written testimonials (non Etruscan writers are significant, of course, but biased). Fortunately, we may study the archaeological, iconographic and epigraphic pieces of evidence to discover the reality of both Etruscan life and death. We can approach the Etruscan funerary practices thanks to the architectural investigation of necropolises and graves, ${ }^{3}$ the archaeological analysis of material left to the deceased ${ }^{4}$ and the iconographic study of the images in the tombs (frescoes, figured vases, mirrors...). ${ }^{5}$ The beautiful Etruscan frescoes allow us to understand the funeral feast in Archaic, Classical and Hellenistic times. ${ }^{6}$ In Archaic and Classical times, merry revelers, aristocratic couples and large number of servants are present in a luxurious symposion, with athletic competitions, dancing and varied games like the famous «Persu Game ». For some scholars, these pictorial motifs refer to funerary rituals, after the moment of death and before the burial of the deceased. In Hellenistic times, around the middle of the 4 th century, these dynamic scenes move to austere presentations from the nether world. If the understanding of the evolution of the Etruscan attitude towards death (function of funeral rituals and meaning of eschatological vision) is given by funeral frescoes, the archaeological material contributes to information on the dead person's status but also on certain details of the funeral practices. ${ }^{4}$ As in the Greek world, Etruscan tombs display two major categories of vases: the perfume vases and the wine set. ${ }^{7}$ The perfumed oil and the wine represent the most known organic products of the Greek civilization. Adopted early by the Etruscans, they are integrated into their everyday life and into their most important religious and funeral rituals. It is usually acknowledged that the vases in the tomb were used in the principal ceremonies of the funerals (prothesis for the perfume vases and banquet for the wine vases) ${ }^{4}$ In fact, nothing is less certain. Based on several combined indices, we argue that at least a part of the ceramic material enclosed with the deceased in the grave, is closely connected with the ultimate moments of the funerals. Moments which introduce the definitive separation with the non-verbal behavior of purification? When the usual sources remain silent on the final act of the Etruscan funerals, using a multidisciplinary approach is necessary by performing a chemical analysis of the contents of the vases (analysis of ancient compounds absorbed into ceramics). Thus, this paper aims at presenting the results of chemical data of the contents of ceramics of the funeral service and to discuss about the real functions of these vases in the ritual.

\section{The tomb and the archaeological material}

In June 2012, the superintendence organized an emergency campaign of archaeological excavations in the Tegola Dipinta area, south of the Banditaccia Necropolis (city of Cerveteri Figure 1). In the south perimeter of the exceptional Tumulus III, after his abandonment, a funeral district was developed mid-way through the IV century. Leaned against the tambour of the tumulus, the Tomb of the Cippi Iscritti has a stairway dromos which leads to the rectangular burial chamber (Figure 2). A beach, hosting 19 or 20 funeral beds, was placed along the four sides of the walls. Though the generality of skeletons was degraded, the sexual identity was established for 3 men and 2 women. ${ }^{8}$ The Etruscan Hellenistic ceramics were found at 2 locations: on the floor of the tomb and in a deep rectangular pit (at the back of the room, in the axis of the door). 8 ceramics of the tomb have been analyzed for the knowledge of their contents. 4 blackglazed ceramics ( 2 little bowls and 2 jugs) come from the rectangular pit and 4 unglazed ceramics ( 3 unguentaria and a jug) were found on the soil, right in front of the door. ${ }^{8}$

The three unguentaria (Figure 3(1-3)), with their fusiform and continuous body, the cylindrical neck slightly curved and the medium foot are within the same group (shape B, 12) of Camilli's classification. ${ }^{9}$ Their chronology can be spread out from the last quarter of the IV to the III century. The most appropriate and extensive study about the unguentaria is Anderson-Stojanović's article, ${ }^{10}$ questioning their chronology, function, workshops and trade. The unguentarium represent a special category of ceramics which succeeds, in the end 
of the V century, to the lekythoi. During the Hellenistic period and until the beginning of the Roman Empire, they are numerous in tombs, particularly used in funerals rituals, but also in both houses and sanctuaries. Their function is closely related to the perfumed oil, for anointing the body (living and dead people) and libations for the dead people and the gods. The two little black-glazed jugs (Figure 3(4-5)) have been manufactured in South Etruria workshops, belonging to types well-known in the end of the IV and the first half of the III century. The first, with trefoil mouth, belongs to the shape 5611 of Morel classification and the second, with pinched mouth, to the shape 5731. ${ }^{11}$ Known as oenochoes, these jugs usually contains wine for daily life or for rituals. The third jug (Figure 3(8)) is unglazed but in fine ware with an elegant form. This local rounded mouth shape (shape 5222, from the end of the IV), is often classified in the category of olpe, with a function also related to the wine set. ${ }^{11}$ The two glazed bowls (Figure 3(6-7)) are from a category of little vases classified by Susan I. Rotroff as "saltcellar" in her chapter "Vessels for food service". ${ }^{12}$ The first (Figure 3(6)), with high rounded wall belongs to the shape 2787 the second (Figure 3(7)), with a nipple underside and a convex wall, to shape $2783 .{ }^{11}$ Both are from a local production over a broad chronological range (end IV-III centuries). Revealing the presence of salt is not possible with the chromatography method, nevertheless it will be quite interesting to discover what function this kind of little vase had in the funeral ritual (for condiments, part of solid food or liquid?).

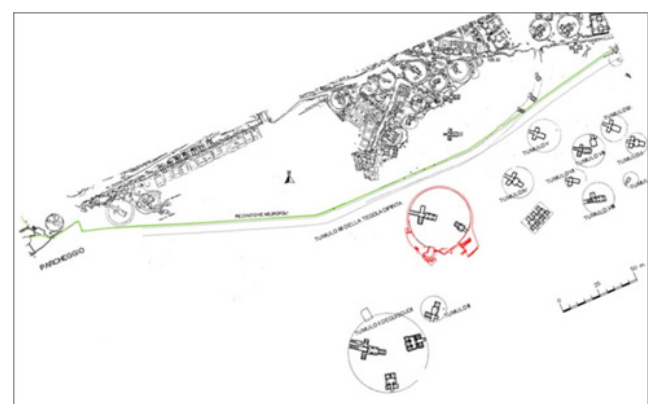

Figure I Plan of the funeral area of Tegola Dipinta, south of the Banditaccia Necropolis (city of Cerveteri). ${ }^{8}$

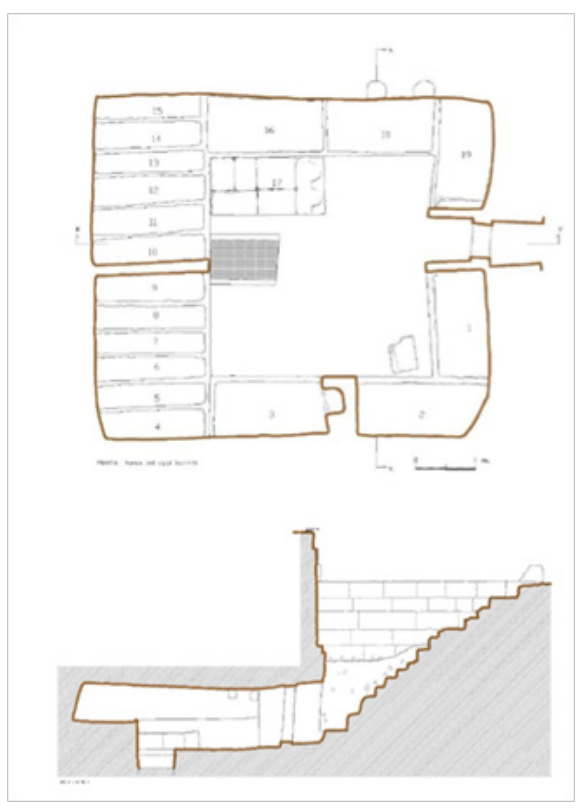

Figure 2 Plan and section of the Cippi Iscritti Tomb. ${ }^{8}$

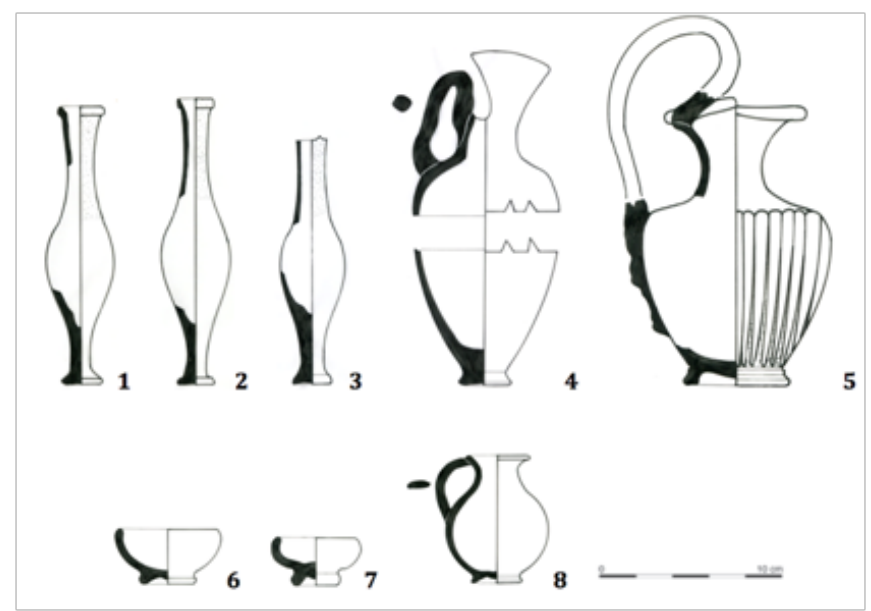

Figure 3 The vases from the Cippi Iscritti Tomb.

\section{Methods}

As part of broader research program on the contents of vases deposited into tombs in pre-Roman Gaul and Italy (MAGI program), organic residue analyses were performed on a set of vases found in the tomb of the Cippi Iscritti in Cerveteri. All the objects have been discovered intact, so the sampling method had to be adapted for such precious objects and must be invisible in order to preserve the aesthetical aspect of the ceramics. Briefly, the objects have been emptied from the low amount of sediment entered since the deposition. Then the inner sides of the ceramics, preferentially the lower part, have been carefully scraped with metallic scalpel to obtain a powder (around $100-250 \mathrm{mg}$ ), immediately stored in an aluminum foil to prevent the sample from any modern contamination. In the lab, the ceramic powder has been submitted to a double-step methodology allowing the characterization of the soluble organic matter but also the insoluble and/or polymerized one. Briefly, an internal standard ( $n$-tricontane, $0.5 \mu \mathrm{g}$ ) was added and the powder is extracted by a mixture dichloromethane/methanol $(1: 1 \mathrm{v} / \mathrm{v})$ under ultrasonication for 30 min. ${ }^{13}$ Then the organic phase was separated from the ceramic by centrifugation and filtered on silica. The organic extract (named first lipid extract, 1LE) was evaporated to dryness under a slight stream of nitrogen. In a second step, the ceramic powder already extracted was submitted to an acido-catalyzed extraction conducted in anhydrous conditions. ${ }^{14} \mathrm{An}$ internal standard ( $n$-cholestane, $0.5 \mu \mathrm{g}$ ) was added. A solution of boron trifluoride in butanol and cyclohexane, used as co solvent, was added and the mixture was maintained at $80^{\circ} \mathrm{C}$ overnight. After cooling, the mixture was extracted with dichloromethane $(3 \mathrm{x}$ $2 \mathrm{~mL}$ ) and the combined organic phases washed with distilled water (2 $\mathrm{x} 2 \mathrm{~mL}$ ), dried by passing through a micro-column of sodium sulphate and evaporated to dryness giving the second lipid extract (2LE). Aliquots of both extracts 1LE and 2LE were derivatized using $50 \mu \mathrm{L}$ $\mathrm{N}, \mathrm{O}$-bis (trimethylsilyl) trifluoroacetamide and $5 \mu \mathrm{L}$ of pyridine, at 70 ${ }^{\circ} \mathrm{C}$, for $1 \mathrm{~h}$ and submitted to gas chromatography (GC) and GC-mass spectrometry (GC-MS) analyses.

GC-MS analyses were performed using a Thermo GC Trace chromatograph and Thermo DSQ II quadripole mass spectrometer. The sample $(1 \mu \mathrm{L})$ was introduced using a split less/split injector set to split fewer modes onto a polydimethylsiloxane column (Phenomenex, ZB-5MSi, $20 \mathrm{~m} \times 0.18 \mathrm{~mm}$ i.d., $0.1 \mu \mathrm{m}$ film thickness). The MS was operated in electron ionization mode at $70 \mathrm{eV}$ with a $\mathrm{GC}$ interface temperature of $300^{\circ} \mathrm{C}$ and a source temperature of $200^{\circ} \mathrm{C}$. The electron energy was $70 \mathrm{eV}$ and data acquisition between $\mathrm{m} / \mathrm{z} 50-800$ at 
6 scans per second. The temperature program was as follows: initial temperature held at $50^{\circ} \mathrm{C}$ for $8 \mathrm{~min}$, followed by an increase to $350^{\circ} \mathrm{C}$ $(10 \mathrm{~min})$ at a rate of $20^{\circ} \mathrm{C} \cdot \mathrm{min}^{-1}$. The acquisition and analysis of the data were carried out using XCalibur software.

\section{Results}

GC-MS analyses of the 1LE extract revealed that all ceramics contained detectable lipids and a very low amount of modern contaminations by synthetic materials, mainly plasticizers (phthalates, alkanes, citroflex...) even for open forms such as bowls. The 1LE consisted mainly on medium- and long-chain fatty acids, long-chain odd $n$-alkanes and even $n$-alkanols. The 2LE showed the presence of aldaric acids from fruits, long-chain fatty acids and even $n$-alkanols from epicuticular waxes.

More in details, the oenochoe $\mathrm{n}^{\circ} 4$ presented a $1 \mathrm{LE}$ consisting on even fatty acids (12:0-18:0) associated with cholesterol and sitosterol/ sitostanol in lower amount, coming respectively from (non-ruminant) animal fat and vegetal fatty material. The total absence of diterpenic markers allowed discarding resin and pitch. Long-chain $n$-alkanols (18-ol-32-ol) revealed few quantities of vegetal waxes coming from the decomposition of the environmental vegetation. The 2LE presented a surprising chromatographic profile consisting of few traces of long-chain even fatty acids (20:0-30:0) and $n$-alkanols (24ol- 30-ol) but mostly a very intense peak of tartaric acid associated with malic acid (Figure 4). The absence of syringic acid orientated to white grapes. Succinic, maleic, fumaric and pyruvic acids indicated an alcoholic fermentation. The combination of markers from white grape and alcoholic fermentation results in a fermented white grape juice, i.e. white wine. As the concentration of tartaric acid is exceptionally high, in regards to the other ceramics analyzed in this same tomb and from other sites, we suggest oenochoe $n^{\circ} 4$ has been deposited full of white wine and placed in vertical position. In this way, the wine has evaporated slowly, the non-volatile molecules letting a very intense chemical fingerprint of wine, dominating all other organic materials present.

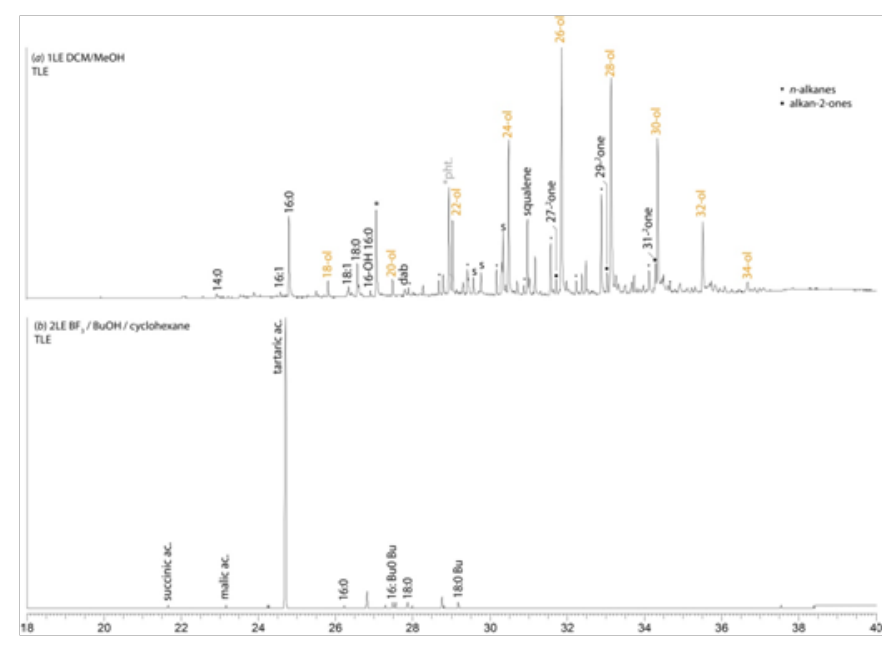

Figure 4 Chromatograms from (a) the ILE and (b) the 2 LE obtained from the organic residues preserved in the inner sides of the jug $n^{\circ} 5$.

Jug $n^{\circ} 5$ presented an interesting 1LE consisting mainly on $n$-alkanols (18-ol-34-ol) showing a Gaussian distribution dominated by the 26-ol, minor quantities of even and linear fatty acids (14:0-18:0) associated with traces of cholesterol (animal origin) and sitosterol (vegetal origin). Traces of free and methylated dehydroabietic acid indicated a small amount of pitch. ${ }^{15}$ The observed long-chain odd ket2-ones $\left(\mathrm{C}_{23}-\mathrm{C}_{31}\right)$ are quite common and have been found in higher plant and phytoplankton biomass and a wide variety of depositional environments such as soils, peats, lacustrine and marine sediments and aerosols. ${ }^{16-18}$ But the distribution of alkan-2-ones in the jug was different from the one observed in peat, shifted to higher components. Also we discard the proposed origin for alkan-2-ones (maximizing at $\mathrm{C}_{19}$ or $\mathrm{C}_{25} / \mathrm{C}_{27}$ ) found in peats, coming from the microbial oxidation of the related $n$-alkanes and/or oxidative decarboxylation of fatty acids derived from plant input. ${ }^{19-21}$ We prefer the hypothesis of a thermal degradation of acyl lipids of vegetal waxes giving aliphatic precursors, such as n-alk-1-enes, which oxidize via the secondary alkanol intermediate to the alkan-2-ones. These compounds have been detected in cooking smoke, Wood burning smoke. ${ }^{22-23}$ They also resulted in vegetal ashes. The 2LE consisted mainly on tartaric acid, as observed for the oenochoe $n^{\circ} 4$. The grape and fermentation markers suggest a white wine. The jug has also contained a mixture of several materials. The relative low amount of fatty acids suggests their loss either by dilution and dissolution by time, or by an anthropic action; in this case we suggest that vegetal material rich in waxes (flowers, leaves, twigs) has been boiled in water with vegetal ashes acting as soap. In this alkaline medium, fatty acids dissolve and are lost although neutral molecules ( $n$-alkanols, $n$-alkanes, sterols) are preserved. Then, white wine can represent a successive content.

Bowls $n^{\circ} 6$ and $n^{\circ} 7$ presented even fatty acids with a greater amount of unsaturated one for the bowl $\mathrm{n}^{\circ} 7$ (different isomers of oleic acid) associated with an intense peak of cholesterol, showing fats from non-ruminant animals and a very high quantity of tartaric acid, associated with malic acid. Neither syringic acid is detected nor fermentation markers and resinous markers. Their absence, coupled with the presence of tartaric and malic acids induces the presence of a product from white grape and the absence of a waterproofing lining in the objects.

Olpè $\mathrm{n}^{\circ} 8$ showed the characteristic association of beeswax biomarkers: odd $n$-alkanes $\left(\mathrm{C}_{21}-\mathrm{C}_{33}\right.$ dominated by the $\left.\mathrm{C}_{27}\right)$, even $n$-alcohols (24-ol-32-ol, each marker being in quasi similar proportion), monoesters derived from palmitic acid (M40-M50), ( $\alpha, \omega-$ 1)-diols in $\mathrm{C}_{24}$ to $\mathrm{C}_{32}$ dominated by the $(\alpha, \omega-1)-\mathrm{C}_{24}$-diol, all detected in the $1 \mathrm{LE}$ and 15 -hydroxypalmitic acid and 14-hydroxypalmitic acid detected in the 2LE. Odd ket-2-ones $\left(\mathrm{C}_{25}-\mathrm{C}_{33}\right)$ are also detected but long-chain free fatty acids of beeswax (24:0-32:0) are quite absent. The GC-MS analysis highlights a small amount of $\mathrm{C}_{16}-\mathrm{C}_{18}$ fatty acids and cholesterol. The absence of fatty acids from beeswax and the preservation of those from an animal fat reveals an alkaline treatment of the materials (here beeswax) by vegetal ashes, conducing to the loss of the fatty acids by dissolution. Beeswax could have been used as waterproofing agent for the porous object. Vegetal ashes could have been mixed together, or added after as a soap to clean the olpe. Then the jug has been filled up with white wine, identified by the association of white grape markers and fermentation markers.

The unguentaria $\mathrm{n}^{\circ} 1-3$ presented three different chromatograms for their 1LE. The first one was characterized by a very large distribution of even and odd fatty acids (6:0-18:0), linear and ramified, associated 
to phytanic and 4,8,12-TMTD acids and cholesterol, corresponding to dairy products. ${ }^{24-25}$ No diterpenic or triterpenic marker was detected, discarding all resinous and plant materials. The 2LE showed traces of only tartaric acid, too tiny to suggest its attribution to a grape derivative content. Also, the unguentarium $\mathrm{n}^{\circ} 1$ seems to have contained milk or a dairy product. The unguentarium $n^{\circ} 2$ revealed an uncommon high and major oleic acid, present as different isomers and even fatty acids (14:0-18:0) associated to abundant cholesterol. They were issued from a non-ruminant animal fat. Disaccharides dominated by mycose were also present as the major preserved markers and attributed to environmental pollutions coming from the cellular walls of soil bacteria. ${ }^{26-27}$ Few amounts of palmitates, palmitoleates and stearates of long-chain alcohols were detected, coming from vegetal waxes and considered as environmental pollutions. Also, squalene was present in very high amounts, observed only as traces in the other ceramics. Its attribution to modern pollution by handling and manipulating the ceramic cannot be retained because of the fine preservation of the container, its narrow opening and long neck; no contact with hand and skin can be retained. Amongst the possible source, squale liver oil can be discarded, but also olive derivatives in regard to the absence of sitosterol and other triterpenoids from olive. The only source is sebum skin; associated to the very high amount of fatty acids and cholesterol, squalene could be issued from the same material, in this case a meat-based piece with skin. The 2LE showed the same abundant fatty acids with the predominating oleic acid and a minor amount of tartaric and malic acids. The content of the unguentarium $\mathrm{n}^{\circ} 2$ doesn't correspond to perfume oil, but a recipe made from nonruminant meat-base piece with skin and white grape juice. Only a few traces of dehydroabietic acid were detected, indicating the addition of a few amount of coniferous resin. Finally, the unguentarium $n^{\circ}$ 3 showed a high proportion of fatty acids, odd and even, linear and branched, with a medium-range distribution (12:0-18:0) associated to abundant cholesterol and squalene. The vegetal waxes were present as minor compounds and attributed to environmental contaminations. In the $2 \mathrm{LE}$, fatty acids and alcohols of vegetal waxes were present in few amounts and tartaric acid was present as minor compound. This unguentarium seemed to have contained a recipe made from ruminant meat-base morsel with skin, a small quantity of white grape juice and of coniferous resin, without any addition of vegetal oil.

\section{Discussion}

To our knowledge, this is the first time that analyses are carried out to investigate the contents of Hellenistic Black Glaze ceramics. Expected vessel contents are wine for the jugs (oenochoes and olpe), perfumed oil for the unguentaria and condiments for the little bowls. In fact, the results unveil a more complex situation (Table 1), without any doubt due to the complexity of the funeral ritual. The white grape is the principal product identified, present inside 6 ceramics, including 2 unguentaria. 4 ceramics present the common characteristic of white grape markers without fermented markers. The absence of specific fermented markers does not show necessarily the absence of wine. In antiquity, the wine differs significantly from our wine categories. Certain wines, named "sweet wines", contain so little alcohol $\left(2-3^{\circ}\right)$ they may not have retained fermented markers. We think that the grape product in the 4 vases is not a juice, but a weak and smooth wine. White wine is identified into our Etruscan Hellenistic ceramics, which is to be expected given that Roman wine was white in general, without proof in specialized Latin literature of specific red wine preparation..$^{28-29}$ Thus, the little 3 jugs and the 2 little bowls represent a wine set, related to the final funeral offering (knowing that the oenochoe 4 was deposed full of wine in the tomb). In addition, oenochoe 5 indicates a small amount of pitch. Pitch presence can be proof of a wine transport in amphora (waterproofed with pitch) or the result of additional coniferous pitch in the wine to give a resinated flavor. Pitch or other form of waterproof is unnecessary into a glazed oenochoe contrary to the unglazed jug $\left(\mathrm{n}^{\circ} 8\right)$. Beeswax was used to rectify the porous nature of the ceramic paste. In two cases (5 and 8), vegetable ashes (with low amount of fatty acids showing an anthropic transformation) can demonstrate the practice of cleansing the vases. Appropriate interpretations on the important presence of animal fats in the little bowls are difficult. There are two possibilities: the first is the presence in every bowl of a food offering (piece of meat, egg...); the second is a natural contamination from the tomb. In a fundamental article, ${ }^{30}$ Tania Oudemans presents the various sources of ceramics contamination. After deposition in a closed environment such as a tomb, the vessel is in direct or indirect contact with organic materials that break down slowly. The food offerings (fish, meat, eggs...) represent natural factors of contamination. The multiple origins of contaminations in a grave context could explain, in some cases, the presence of animal fats in the ceramics. The open shapes like the bowls are most susceptible to contamination risks than the closed shapes. This makes it difficult to decide between the hypothesis of food offering (last utilization of the vases) and that of contamination (piece of meat in overhead position for example). With this problem of interpretation of animal fats, we end up with the unguentaria contents. In the first we have a particular animal fat category (dairy product) and in the second and third unguentaria of subcutaneous fat. But in neither case do we have the expected result the expected result of perfumed oil or simply vegetal oil. Considering that, in the 2 unguentaria ( 2 and 3 ) the animal fats are in large quantities and are specific (both meat-base piece with skin), we consider it to be unlikely they can represent contaminations (especially in closed shapes like unguentaria). Then, for the 3 unguentaria, the perfumed oil is substituted by animal products: dairy product for the first and animal fats for the last two others. For the first, we suppose this simple product to be milk as the elongated narrow shape does not allow introducing solid matter like cheese. For the second and third, we think it could be a mixture of animal fat, coniferous resin and grape product which could be sweat wine. What can these results mean about the function of the unguentaria? Our Italian colleagues found interesting data from the case study of 13 ceramic unguentaria discovered in 2 Sicilian necropolises. ${ }^{31}$ GC-MS analysis showed difference between two groups of finds: the unguentaria from Adranon show abundant traces of animal lipids used in balm making, while those from Hymera resulted empty (or filled with water). The Sicilian results are equally surprising, given the assumption that these vessels were intended to hold precious perfumed oil. We can suppose that, in contrast to the highly valued perfume vases in alabaster that contain exotic fragrant materials, ${ }^{32}$ the ceramic unguentaria could contain various organic materials (water, milk, basic balm). Far away from the precious Greek and Roman perfumed oils, ${ }^{33}$ the basic balm is made from a mixture of animal fat, sweet wine and coniferous resin, according to our Etruscan unguentaria. It is worth noting that these data are quite similar to those based on the study of Archaic Corinthian vases ${ }^{34}$ (except for the wine, but the protocol of wine markers identification did not exist at the time) 
Table I Results of the analyses

\begin{tabular}{|c|c|}
\hline \multirow[t]{2}{*}{ Unguentarium Figure $3(I)$} & Dairy product (milk?) \\
\hline & Non ruminant animal fat (large quantities) \\
\hline \multirow[t]{3}{*}{ Unguentarium Figure $3(2)$} & White grape (without fermented markers) \\
\hline & Coniferous resin (small quantities) \\
\hline & Ruminant animal fat (large quantities) \\
\hline \multirow[t]{3}{*}{ Unguentarium Figure $3(3)$} & White grape in small quantities (without fermented markers) \\
\hline & Coniferous resin (small quantities) \\
\hline & Non ruminant animal fat (small quantities) \\
\hline \multirow{3}{*}{ Oenochoe Figure 3(4) } & Fermented white grape (white wine in large quantities) \\
\hline & Animal fat (small quantities) \\
\hline & Pitch (small quantities) \\
\hline \multirow{3}{*}{ Oenochoe Figure 3(5) } & Vegetal ashes \\
\hline & Fermented white grape (white wine) \\
\hline & Non ruminant animal fat (large quantities) \\
\hline \multirow{2}{*}{ Bowl Figure 3(6) } & White grape (without fermented markers) \\
\hline & Non ruminant animal fat (large quantities) \\
\hline \multirow{3}{*}{ Bowl Figure 3(7) } & White grape (without fermented markers) \\
\hline & Beeswax (large quantities) \\
\hline & Vegetal ashes \\
\hline \multirow{2}{*}{ Olpe Figure 3(8) } & Fermented white grape (white wine) \\
\hline & Animal fat (small quantities) \\
\hline
\end{tabular}

\section{Conclusion}

In an article with a meaningful title "Organic residue analysis in archaeology: the archaeological biomarker revolution", 35 Professor Richard P. Evershed writes "Thus, we are now at the stage where in order to provide archaeologically meaningful interpretations we must begin to forge stronger connections between the residues that we observe and the cultural and social attributes of the individuals and communities that produced them". This is precisely the case for understanding the effective use of ceramics in Etruscan funeral rituals. Thanks to the analysis of ancient compounds absorbed by ceramics we can demonstrate that, for the Hellenistic tomb of Cippi Iscritti:

a. The white wine is the principal product used in funeral ritual

b. Dairy product (doubtless milk as pointed out by texts) is also offered to the dead

c. The precious perfumes evidenced by Latin texts can be replaced by low-priced balms

d. These analysis also provide technical data on the real use of ceramics

e. The interior of an unglazed jug was waterproofed by beeswax

f. The interior of 2 ceramics was probably cleansed with vegetal ashes

\section{Acknowledgements}

We would like to thank our Italian colleagues, Rita Cosentino and Alfonsina Russo who allowed us to study the archaeological material and our University colleague Maryse Butel who proofreaded our English text.

\section{Conflict of interest}

Author declares there is no conflict of interest in publishing the article.

\section{References}

1. Leighton R. Urbanization in southern Etruria from the tenth to the sixth century: the origin and growth of major centers. In: Macintosh TJ. editor. The Etruscan World, Routledge, USA; 2013. p. 134-150.

2. Jolivet V. A long twilight: “Romanization” of Etruria. In Macintosh TJ, editor. The Etruscan World, Routledge Handbooks online, USA; 2013. p. $151-180$.

3. Steingräber S. Worshiping with the dead: new approaches to Etruscan necropoleis. In: Macintosh TJ, editor. The Etruscan World. Routledge Handbooks online, USA; 2013. p. 672-682.

4. Frere D. Book Review of Les potiers d'Étrurie et leur monde: Contacts, échanges, transferts. Hommages à Mario A. Del Chiaro. $A J A$. 2016;120(4):488. 
5. Rasmus BJ. Passage to the Underworld. Continuity or Change in Etruscan Funerary Ideology and Pratices $\left(6^{\text {th }}-2^{\text {nd }}\right.$ Centuries BC)? In: Rasmus BJ, Prusac M, et al. editors. Death and Changing Rituals. Function and Meaning in Ancient Funerary Practices. Oxford, Philadelphia, UK; 2016. p. $105-184$.

6. Rathje A. The banquet through Etruscan history. In: Macintosh TJ, editor. The Etruscan World, Routledge, USA; 2013. p. 823-840.

7. Frere D. Parfums, huiles et crèmes parfumées en Etrurie orientalisante. Mediterranea. 2006;3:87-119.

8. Cosentino R, Quaranta P, Russo A.Archeologia e Scienza: La tomba dei cippi iscritti di Cerveteri. In: Mercuri L, Zaccagnini R, editors. Etruria in progress: La ricerca archeologica in Etruria meridionale. Italy; 2008. p. $87-96$.

9. Camilli AC. Ampullae. Balsamari ceramici di età ellenestica e romana. Fratelli Palombi Editori, Rome, Italy; 1999. p. 152.

10. Anderson SVR. The chronology and function of ceramic unguentaria AJA. 1987;91(1):105-122.

11. Morel JP. Céramique campanienne: les formes. Ecole française de Rome, Rome, Italy; 1994. p. 243-246.

12. Rotroff SI. The Athenian Agora. Results of Excavations conducted by the American School of Classical Studies at Athens. vol 29. Hellenistic Pottery: Athenian and Imported Wheel made Table Ware and Related Material, American School of Classical Studies at Athens, USA; 1997. p. 574 .

13. Charters S, Evershed RP, Blinkhorn PW, et al. Evidence for the mixing of fats and waxes in archaeological ceramics. Archaeometry. 1995;37(1):113-127.

14. Garnier N, Valamoti SM. Prehistoric wine-making at Dikili Tash (Northern Greece): Integrating residue analysis and archaeobotany. Journal of Archaeological Science. 2016;74:195-206.

15. Evershed RP, Jerman K, Eglinton G. Pine wood origin for pitch from the Mary Rose. Nature. 1985;314(6011):528-530.

16. Hernandez ME, Mead R, Peralba MC, et al. Origin and transport of nalkane-2-ones in a subtropical estuary: potential biomarkers for seagrassderived organic matter. Organic Geochemistry. 2001;32:21-32.

17. Tuo J, Li Q. Occurrence and distribution of long-chain acyclic ketones in immature coals. Applied Geochemistry. 2005;20:553-568.

18. Bai Y, Fang X, Wang Y, et al. Distribution of aliphatic ketones in Chinese soils: potential environmental implications. Organic Geochemistry. 2006;37(7):860-869.

19. Allen JE, Forney FW, Markovetz AJ. Microbial subterminal oxidation of alkanes and alk-1-enes. Lipids. 1971;6(7):448-452.

20. Lehtonen K, Ketola, M. Occurrence of long-chain acyclic methyl ketones in Sphagnum and Carex peats of various degress of humification Organic Geochemistry. 1990;15(3):275-280.
21. Volkman JK, Gllan FT, Johns RB, et al. Sources of neutral lipids in a temperate intertidal sediment. Geochimica et Cosmochimica Acta. 1981;45(10):1817-1828.

22. Rogge WF, Lynn MH, Monica AM, et al. Sources of fine organic aerosol. 1. Charbroilers and meat cooking operations. Environ Sci Technol. 1991;25(6):1112-1125.

23. Standley LJ, Simoneit BRT. Characterization of extractable plant wax, resin, and thermally matured components in smoke particles from prescribed burns. Environ Sci Technol. 1987;21(2):163-169.

24. Isaksson S, Hallgren F. Lipid residue analyses of Early Neolithic funnel-beaker pottery from Skogsmossen, eastern Central Sweden and the earliest evidence of dairying in Sweden. Journal of Archaeological Science. 2012;39(12):3600-3609.

25. Heron C, Nilsen G, Stern B, et al. Application of lipid biomarker analysis to evaluate the function of "slab-lined pits" in Arctic Norway. Journal of Archaeological Science. 2010;37(9):2188-2197.

26. Rogge WF, Medeiros PM, Simoneit BRT. Organic marke compounds in surface soils of crop fields from the San Joaquin Valley fugitive dust characterization study. Atmospheric Environment. 2007;41(37):8183-8204

27. Rogge WF, Medeiros PM, Simoneit BRT. Organic marker compounds for surface soil and fugitive dust from open lot dairies and cattle feedlots. Atmospheric Environment. 2006;40(1):27-49.

28. Brun JP, Tchernia A. Vendanges et vinification. In: Brun JP, et al. editor Le vin Nectar des Dieux. Génie des Hommes, Infolio Editions, France; 2004. p. 232-249.

29. Thurmond D. From Vines to Wines in Classical Rome. A Handbook of Viticulture and Oenology in Rome and the Roman West. Brill, USA; 2016.

30. Oudemans TFM. Applying organic residue analysis in ceramic studies - a functional approach. Leiden Journal of Pottery Studies. 2007;23:5-20.

31. Agozzino P, Avellone G, Donato I, et al. Identification of Organic Compounds in Fictile Unguentaria from two Sicilian Necropolis of Greek Age (5th Century b.C.) by GC-MS Analysis. Ann Chim. 2007;97:859-865.

32. Colombini MP, Giachi G, Iozzo M, et al. An Etruscan ointment from Chiusi (Tuscany, Italy): its chemical characterization. Journal of Archaeological Science. 2009;36(7):1488-1495.

33. Brun JP. The production of perfumes in antiquity: the cases of Delos and Paestum. AJA. 2000;104(2):277-308.

34. Biers WR, Gerhardt KO, Braniff RA. Lost Scents: Investigations of Corinthian "Plastic" Vases by Gas Chromatography-Mass Spectrometry. University of Pennsylvania, Museum of Archaeology and Anthropology, Pennsylvania, USA; 1994. p. 72.

35. Evershed RP. Organic Residue Analysis in Archaeology: the Archaeological Biomarker Revolution. Archaeometry. 2008;50(6):895-924. 